\title{
Peripapillary venous drainage from the choroid: a variable feature in human eyes
}

\author{
Gordon L Ruskell
}

\begin{abstract}
Aims/background-Drainage of blood from the choroid is thought to occur exclusively through the vortex veins in the absence of a venous equivalent of the posterior ciliary arteries. A chance observation in the peripapillary region of the choroid, inconsistent with this concept, suggested that the subject required review.

Methods-Ten nerve heads from 10 individuals were examined histologically using interrupted serial resin sections. They were obtained from eyes free of posterior segment pathology.

Results-Peripapillary veins varying in number and size were present in seven preparations and none in the other three. All veins penetrated the sclera from the choroid close to the optic nerve head and entered the pia mater directly, receiving small veins from the laminar and postlaminar nerve head. No other locations of posterior venous penetrations of the sclera were found. This is the first description of these vessels in normal eyes; they are named 'choroidopial veins'. Conclusions-Choroidopial veins represent a minor and inconstant route for blood drainage from the choroid, with a role in optic nerve head circulation. (Br f Ophthalmol 1997;81:77-79)
\end{abstract}

The eye does not possess a posterior system of ciliary veins equivalent to that of the arteries and, consequently, drainage of blood from the choroid is usually stated to occur exclusively through the vortex veins. ${ }^{1-4}$ Leber, ${ }^{5}$ in his landmark account of the vasculature of the eye, made no reference to posterior venous drainage other than from the episclera. Anderson's histological and latex infusion studies ${ }^{67}$ revealed a venous link between the prelaminar nerve head and choroid in primates but he found no venous exit from the sclera. Against this firm concept of venous anatomy is set a number of reports describing exceptional and anomalous cases in which posterior venous drainage was noted. For example, Schoute ${ }^{8}$ described a highly myopic patient with a large choroidal vein entering the disc and draining with the substantially smaller retinal veins. Other reports of a similar nature but not invariably coincident with myopia, described large posteriorly draining choroidal veins either encroaching the disc or taking a peripapillary route. They were referred to as choriovaginal or posterior vortex veins ${ }^{9-12}$ These mainly oph- thalmoscopic observations were augmented by a histological study demonstrating a very large vein leaving the eye posteriorly and entering the pia mater directly. ${ }^{13}$ Most of these cases were grossly anomalous and cannot be considered to challenge the general observation that in healthy eyes posterior ciliary veins are absent.

The present study was prompted by inspection of histological material prepared for teaching purposes which revealed a pattern of peripapillary veins inconsistent with the accepted anatomy. Further material was obtained and a systematic search for peripapillary venous exits from the eye made.

\section{Materials and methods}

Ten optic nerve heads from 10 individuals, 12-82 years of age, were prepared for histological examination. Five eyes were removed for various conditions (Table 1) and fixed by immersion in 3\% phosphate buffered glutaraldehyde; another was fixed in $10 \%$ buffered formaldehyde. In the two eyes that became available following orbital exenteration for sinus carcinoma, there was no evidence of orbital venous congestion or ocular proptosis. Four donor eyes were used, each of them stored in normal saline in a refrigerator and subsequently fixed in a $2 \%$ glutaraldehyde $/ 3 \%$ paraformaldehyde mixture. Although tissue preservation was inevitably rather poor in the donor eyes, they were found to be adequate for the purposes of this study. The pathology of one of the specimens was unrecorded and in the remainder there was no record of optic nerve disease. Tissues were trimmed leaving an optic nerve stump at the nerve head at least $2 \mathrm{~mm}$ in length with a collar of sclera, with choroid and retina attached. Tissues were washed over-

Table 1 Incidence of choroidopial veins

\begin{tabular}{|c|c|c|c|c|}
\hline Reference & Age & $\begin{array}{l}\text { Section } \\
\text { orientation }\end{array}$ & $\begin{array}{l}\text { No of } \\
\text { veins }\end{array}$ & Pathology \\
\hline Col 2 & Unknown & TS & 1 & Unknown \\
\hline Col 3 & 45 & LS & $3+$ & $\begin{array}{l}\text { Melanoma } \\
\text { (choroid) }\end{array}$ \\
\hline HG7 & 82 & TS & 10 & $\begin{array}{l}\text { Carcinoma } \\
\text { (maxilla) }\end{array}$ \\
\hline HG8 & 55 & TS/LS & 11 & $\begin{array}{l}\text { Carcinoma } \\
\text { (ethmoid) }\end{array}$ \\
\hline HG10 & 70 & LS & 3 & $\begin{array}{l}\text { Melanoma } \\
\text { (conjunctiva) }\end{array}$ \\
\hline HW 17 & 21 & $\mathrm{TS} / \mathrm{LS}$ & 3 & $\begin{array}{l}\text { Perforating } \\
\text { injury }\end{array}$ \\
\hline HW21 & Unknown & LS & 0 & Donor \\
\hline HW 22 & 12 & TS & 2 & Donor \\
\hline AM1 & 38 & TS & 0 & Donor \\
\hline $\mathrm{AM} 2$ & 60 & LS & 0 & Donor \\
\hline
\end{tabular}

$\star$ Number of choroidopial veins at the level of the pia mater. tOnly half of the nerve head was examined.

TS = transverse section; LS = longitudinal section. 


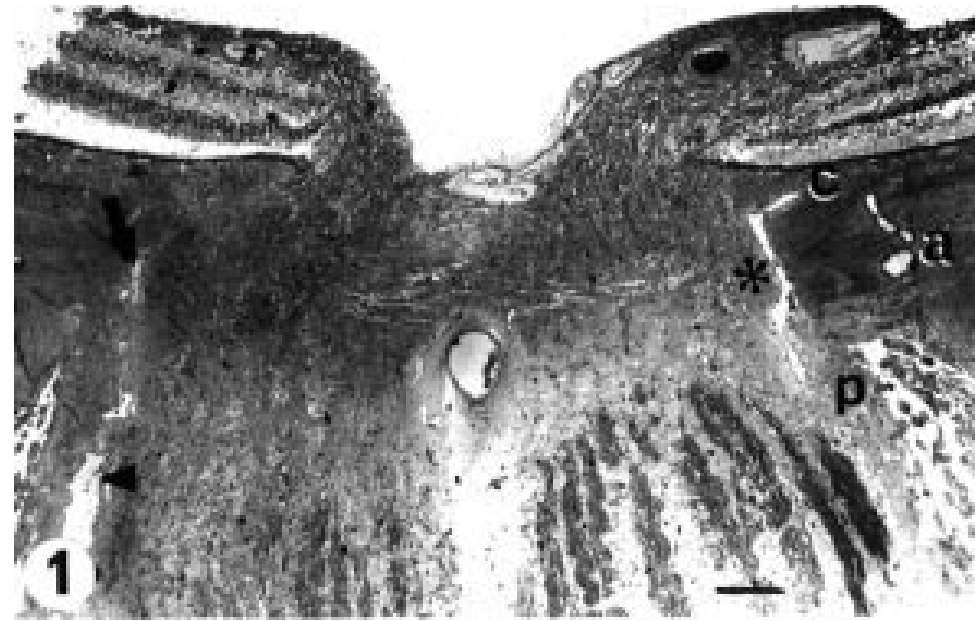

Figure 1 Longitudinal section of the optic nerve head. A choroidopial vein (asterisk) passes from the choroid (c) to the pia mater ( $p$ ). Part of the path of a similar vessel (arrow) on the other side (also traced from the choroid) that continued to a large pial vein (arrowhead). $a=$ ciliary arteries. Ref Col 2. Bar $=0.25 \mathrm{~mm}$.

night, immersed in an unbuffered solution of $1 \%$ osmium tetroxide for 1 hour, washed briefly, dehydrated in graded ethanols, cleared in xylene, and embedded in Araldite.

Interrupted $1 \mu \mathrm{m}$ serial sections were cut on an ultramicrotome in the frontal plane (transversely) or longitudinally as indicated in Table 1. Every fifth section was collected in longitudinally cut material and every tenth when transversely cut. Full serial sections were collected occasionally when warranted. Two of the nerves were divided longitudinally in the vertical meridian before embedding to permit sectioning of one half longitudinally and the other transversely (indicated TS/LS in the table). Sections were treated with sodium methoxide to remove the resin then stained in $1 \%$ toluidine blue in an equal volume of $2.5 \%$ sodium carbonate and examined with a light microscope.

\section{Results}

Veins were found in seven of the 10 nerve heads passing from the peripapillary choroid, penetrating the sclera adjacent to the optic

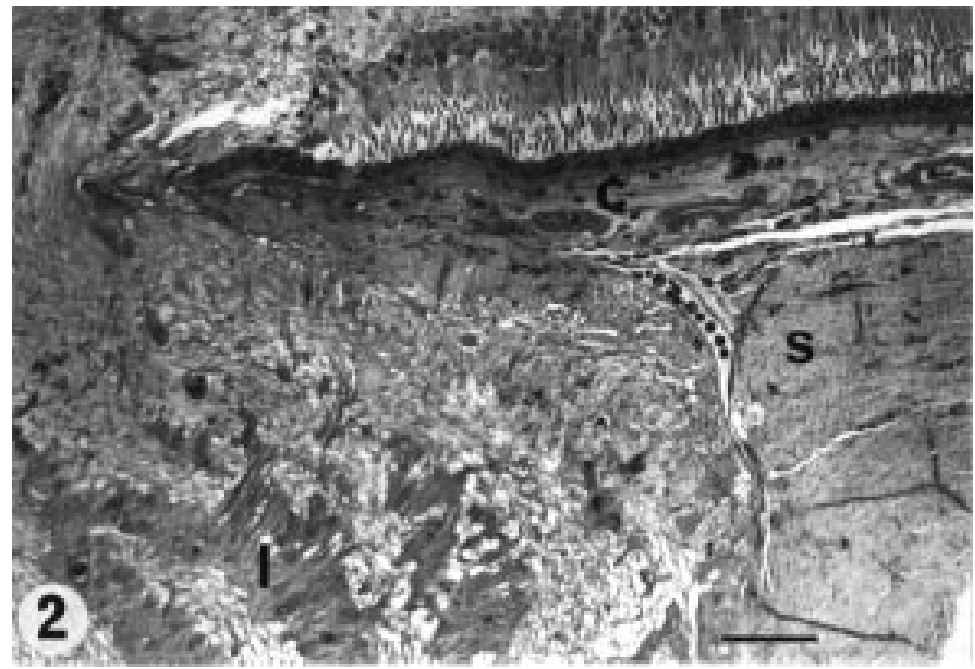

Figure 2 Part of an optic nerve head sectioned longitudinally. A fine blood-filled choroidopial vein passes from the choroid (c) through the sclera (s) to enter the pia mater. $l=$ lamina cribrosa. Ref HG8. Bar $=100 \mu \mathrm{m}$.

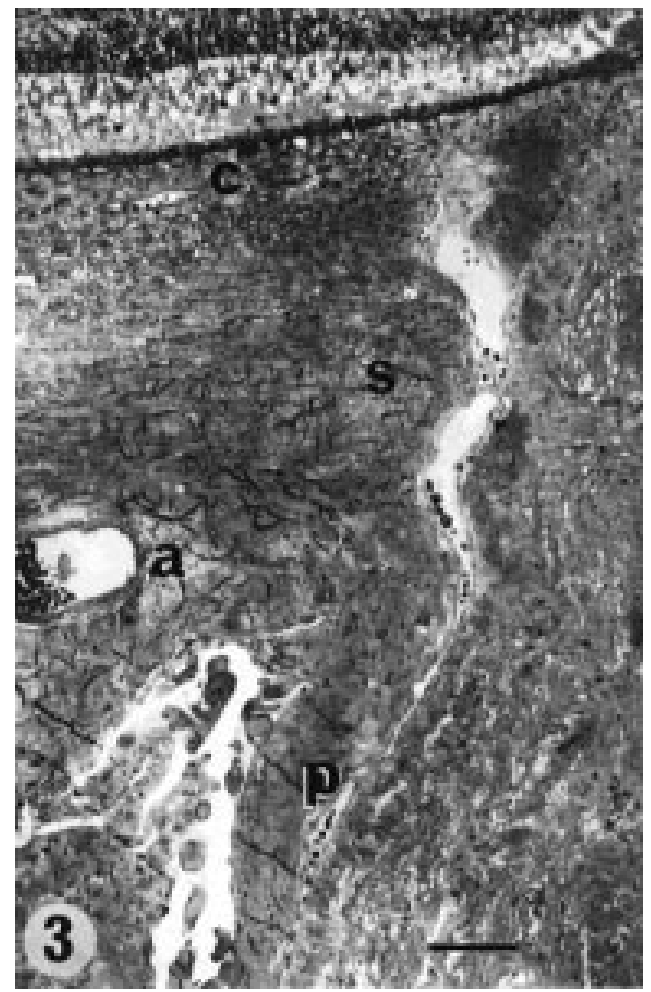

Figure 3 A substantial choroidopial vein takes a similar course to that shown in Figure 1. a = ciliary artery, $c=$ choroid, $p=$ pia mater, $s=$ sclera. Ref Col 3. Bar $=$ $100 \mu \mathrm{m}$.

nerve and entering the pia mater directly (Table 1). Veins taking this route in the anomalous examples referred to in the introduction were often called choriovaginal veins, but the term choroidopial is more precisely expressive and will be used in this paper.

All choroidopial veins penetrated the sclera within $100 \mu \mathrm{m}$ of the nerve head and therefore very close to the scleral canal. They passed posteriorly from the outermost layer of the choroid and therefore did not traverse the border tissue of Jacoby separating the choroid from the optic nerve head. Several examples of veins penetrating the sclera and reaching the pia mater without branching were traced (Figs 1-3). They varied in diameter from approximately $10-90 \mu \mathrm{m}$, measured at their entry into the pia mater, four eyes displaying at least one vein at the upper end of the size range. Further along the pia mater veins were sometimes seen to expand substantially, maximally reaching $110 \mu \mathrm{m}$ in diameter; the increased calibre was not attributable to convergence of veins. Several choroidopial veins divided at least once after leaving the choroid, the branches fanning out to produce several small pial veins. In the half optic nerve preparation of Figures 4 and 5, seven pial veins derived from three choroidal veins were traced and several more were identified in the other longitudinally sectioned half, issuing from two further choroidal veins. Branching occurred in all the choroidopial veins of two preparations, in a single instance in two others and only undivided veins were noted in the remaining three.

In one preparation only one small vein and in another two small $(<20 \mu \mathrm{m})$ choroidopial 

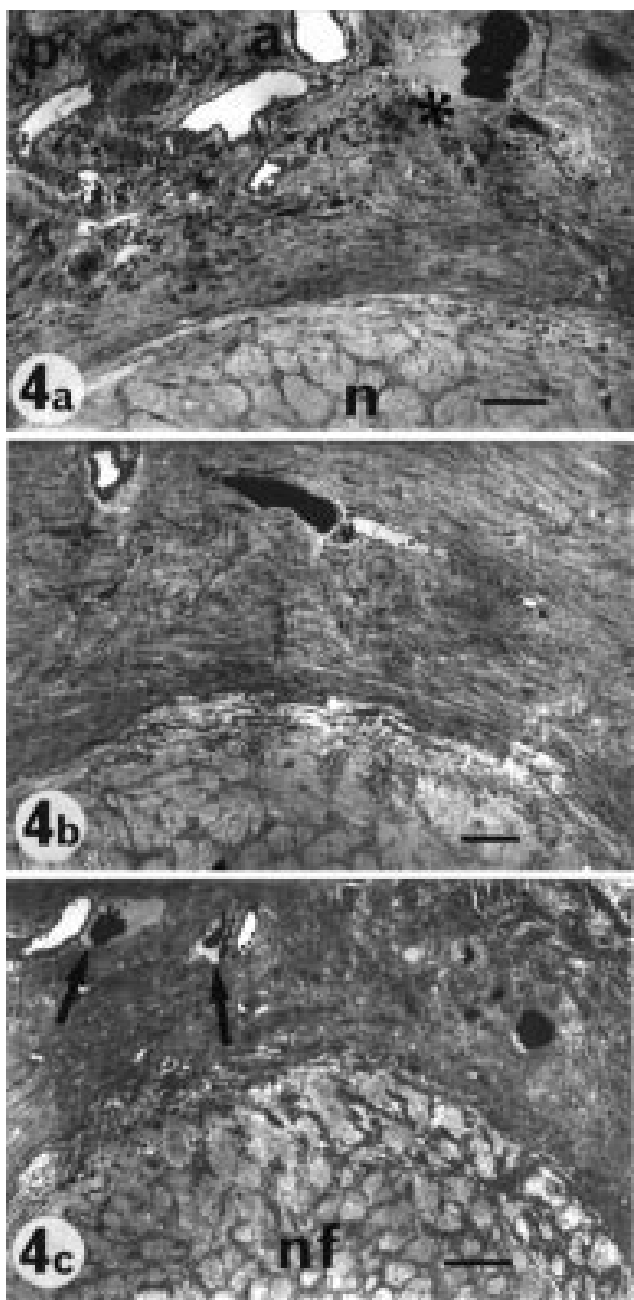

Figure 4 A sequence of transverse sections through a segment of an optic nerve head to show the passage of choroidopial veins from the choroid in section (a), and choroidopial veins from the choroid in section (a), and
through the sclera in (b) and (c). A branch from a large choroidal vein (partly blood filled, asterisk) divides in (b) and the branches approach the optic nerve in (c) where two further veins, also traced from the choroid, are shown (arrows). $a=$ choroidal arteries, $n=$ prelaminar optic nerve, $n f=$ optic nerve at commencement of lamina cribrosa, $p=$ choroidal pigment Ref HG7. Bars $=100 \mu \mathrm{m}$, $100 \mu \mathrm{m}, 200 \mu \mathrm{m}$

veins were present, and in three of the 10 preparations no choroidopial veins could be traced (Table 1).

The structure of veins was unchanged throughout their course from choroid to pia

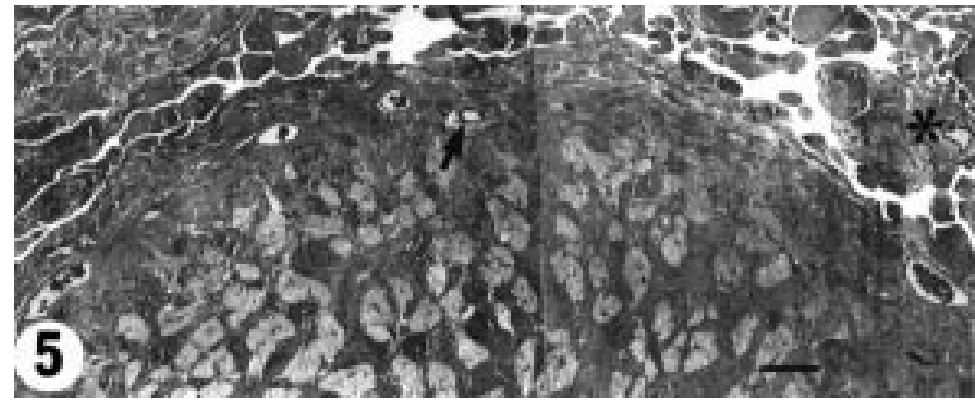

Figure 5 The pia mater of the optic nerve, continuing the sequence from Figure 4. All the pial vessels shown are veins (all derived from three choroidal veins) except one (arrow) which is a recurrent branch from an intrascleral ciliary artery. Another recurrent artery (asterisk) lies in a trabecula of the arachnoid mater-it later entered the pia mater. $s=$ sclera. Ref HG7. Bar $=50 \mu \mathrm{m}$. and unvaried within and between specimens. The cellular structure of the venous wall consisted of endothelium and very infrequent pericytes. A thin layer of connective tissue completed the wall. Numerous arterioles, recurrent from the choroid but mostly from intrascleral ciliary arteries and, in particular, the circle of Zinn-Haller, entered the pia mater, but they were easily distinguished from the veins by the thickness of their walls. The arterioles sometimes entered the pia mater directly, in common with the choroidopial veins, but most of them entered arachnoid trabeculae upon leaving the sclera and subsequently transferred to the pia (Fig 5).

As they entered the pia mater, a number of the veins received fine branches from the optic nerve head at lamina and postlaminar levels (Fig 6). The further passage and drainage of the choroidopial veins was not traced.

\section{Discussion}

In a study of this kind it is prudent to consider the possibility of anomalous structures imposed by disease. The propensity for pathological development of new veins or enlargement of existing veins at the optic disc is well documented, in particular the formation of optociliary veins. Most commonly associated with optic nerve sheath meningiomas, these shunt blood from the central retinal vein to the choroid, presumably in response to retrobulbar constriction of the central retinal vein. ${ }^{13-15}$ Such eyes are exophthalmic and blind. It is feasible that the two eyes obtained following orbital exenteration for sinus carcinomas might have been subject to retrobulbar pressure, but no ocular abnormalities were noted in the pathologist's report and the presence of choroidopial veins may be regarded as a normal feature with confidence. That they possessed more, albeit smaller, veins than in some of the other eyes examined was presumably a chance occurrence.

The observations justify the conclusion that posterior venous drainage from the choroid occurs normally in a proportion of eyes. The sample used is too small to comment on frequency but it is stressed that the nerves used were unselected after the initial observation of choroidopial veins. The next nine nerves that became available were used. The anomalous veins referred to in the introduction were

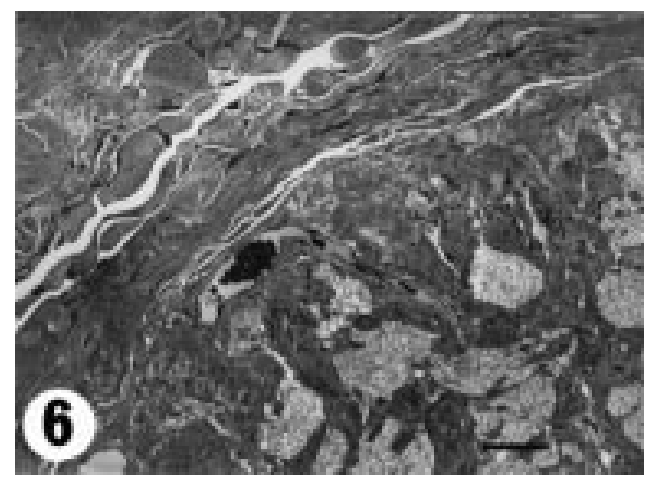

Figure 6 A choroidopial vein receives a branch from the optic nerve head at lamina level. Ref HG7. Bar = 50 $\mu \mathrm{m}$. 
observable ophthalmoscopically because of their exceptional size, but those described in this study are relatively small, pass directly back close to the disc, and are therefore unlikely to be recognised by this means. Without this facility the absence of previous information on choroidopial veins is perhaps not surprising and they were not observed in earlier, including the most recent, histological studies. ${ }^{6717}$ Another technique, scanning electron microscopy of vascular casts, offers the benefit of total vascular display unimpeded by tissues, and it has been applied profitably to the optic nerve head region. ${ }^{18-21}$ The casts effectively demonstrate the arrangement of the principal vessels but distinguishing artery from vein among the confusing density and variety of smaller vessels bordering the intraocular part of the optic nerve must present a problem, which may account for the absence of comment on any venous channels. The present study is the first of its kind to employ thin epoxy resin sections which, although laborious, provide much improved resolution of detail.

If the size of choroidopial veins is compared with that of the vortex veins one is bound to conclude that, at best, they constitute a minor route for choroidal blood drainage. It does not follow that their role is negligible as they clearly facilitate blood flow from the optic nerve head and the lumen of the largest of them nearly compares with that of the central retinal vein.

An assumption has been made that blood flow is directed posteriorly. The alternative is that blood flows from the pia mater and the nerve head to the choroid, then forward to the vortex veins; the divergent branching posteriorly in some veins might be thought to favour this route. Morphology alone cannot provide a definitive answer but forward flow is improbable in view of the expected gradient from low extraocular to high intraocular pressure. No information was gathered or sought on the subsequent passage of blood posteriorly from the pia mater, but the central retinal vein at its exit from the nerve is a probable recipient, and no doubt other lesser vessels drain blood from the nerve to the principal orbital veins.

I am grateful to Dr E Pels, Amsterdam, Professor W Lee, Glasgow, Dr T Makeley, Columbus, Ohio, and Mr K Wang, Luton, for the provision of material.

1 Last RJ. Wolff's anatomy of the eye and orbit. 6th ed. London: Lewis, 1968:149.

2 Hogan MJ, Alvarado JA, Weddell JE. Histology of the human eye: an atlas and text. Philadelphia: Saunders, 1971:533.

Fine BS, Yanoff M. Ocular histology: a text and atlas. 2nd ed. Hagerstown: Harper and Row, 1979:283.

4 Torczynski E. Sclera. In: Jakobiec FA, ed. Ocular anatomy, embryology and teratology. Philadelphia: Harper \& Row, 1982:587-99.

5 Leber Th. Die Cirkulations-und Ernährungsverhältnisse des Auges. In, Graefe- Saemisch Handbuch ges.Augenheilk. des Auges. In, Graefe- Saemisch

6 Anderson DR. Vascular supply to the optic nerve in Anderson DR. Vascular supply to the opti
primates. Am $\mathcal{F}$ Ophthalmol 1970;70:341-51.

7 Anderson DR, Braverman S. Reevaluation of the optic disc vasculature. Am f Ophthalmol 1976;82:165-74.

8 Schoute GJ. Vena vorticosa im hinteren Bulbustheile. Graefes Arch Ophthalmol 1898;46:357-9.

9 Axenfeld, Yamashita. Präparale einen Strudelvene am hinteren Pol eines emmetropen Auges. Ber Dtsch Ophthal Ges 1900;28:194.

10 Thompson WE, Ballantyne AJ. Chorio-vaginal veins in the myope and

11 van Geuns JR. Ein Fall von neugebildeter Vena opticociliaris in Folge von Stauungspapille. Arch Augenheilk ciliaris in Folge

12 Attius G. Hintere Venae vorticosae, Myopie, Amblyopie. Klin Monatsbl Augenheilkd 1912;50:744-9.

13 Coats G. On the pathology of chorio-vaginal (posterior vortex) veins. Ophthalmol Rev 1906;25:99-112.

14 Frisén L, Hoyt WF, Tengroth BM. Optociliary veins, disc pallor and visual loss: a triad of signs indicating spheno-orbital meningioma. Acta Ophthalmol 1973;51: $241-9$.

15 Rodrigues MM, Savino PJ, Schatz NJ. Spheno-orbital meningioma with optociliary veins. Am $\mathcal{F}$ Ophthalmol 1976;81: 666-70.

16 Zakka KA, Summerer RW, Yee RD, Foos RY, Kim J. Optociliary veins in a primary optic nerve sheath meningioma. Am f Ophthalmol 1979;87:91-5.

17 Lieberman MF, Maumenee AE, Green WR. Histologic studies of the vasculature of the anterior optic nerve. Am $\mathcal{F}$ Ophthalmol 1975;82:405-23.

18 Risco JM, Grimson BS, Johnson PT. Angioarchitecture of the ciliary artery circulation of the posterior pole. Arch Ophthalmol 1981; 99: 864-8.

19 Fryczkowski AW, Grimson BS, Peiffer RL. Scanning electron microscopy of vascular casts of the human lamina cribrosa. Int Ophthalmol 1984;7:95-100.

20 Zhao Y, Li F. Microangioarchitecture of the optic papilla. fap F Ophthalmol 1987;31:147-59.

21 Olver JM, Spalton DJ, McCartney ACE. Quantitative morphology of human retrolaminar optic nerve vasculature. Invest Ophthalmol Vis Sci 1994;35:3858-66. 